\title{
Air pollution exposure in early pregnancy and adverse pregnancy outcomes: a register-based cohort study
}

\author{
David Olsson, ${ }^{1}$ Ingrid Mogren, ${ }^{2}$ Bertil Forsberg ${ }^{1}$
}

To cite: Olsson D, Mogren I, Forsberg B. Air pollution exposure in early pregnancy and adverse pregnancy outcomes: a register-based cohort study. BMJ Open 2013:3:e001955

doi:10.1136/bmjopen-2012001955

- Prepublication history and additional material for this paper are available online. To view these files please visit the journal online (http://dx.doi.org/10.1136/ bmjopen-2012-001955).

Received 2 October 2012 Revised 3 December 2012 Accepted 3 January 2013

This final article is available for use under the terms of the Creative Commons Attribution Non-Commercial 2.0 Licence; see http://bmjopen.bmj.com

For numbered affiliations see end of article.

\section{Correspondence to}

David Olsson;

david.olsson@envmed.umu.se

\section{ABSTRACT}

Objectives: Our aim was to study the possible associations between exposure to elevated levels of air pollution, ozone $\left(\mathrm{O}_{3}\right)$ and vehicle exhaust $\left(\mathrm{NO}_{\mathrm{x}}\right)$, during early gestation, and adverse pregnancy outcomes such as pre-eclampsia, preterm birth and small for gestational age.

Design: Prospective register-based cohort study. Setting: The Swedish Medical Birth Register includes data on all deliveries during 1998 to 2006 in Greater Stockholm, Sweden. The national Patient Register and the Prescribed Drug Register were used to collect information on maternal asthma.

Participants: All singleton pregnancies, conceived at the earliest in August 1997 and at the latest in February 2006, were included, $n=120755$.

Outcome measures: We studied preterm birth, small for gestational age and pre-eclampsia.

Results: $4.4 \%$ of pregnancies resulted in a preterm birth. The prevalence of pre-eclampsia was $2.7 \%$. We observed an association between first trimester $\mathrm{O}_{3}$ and preterm birth (OR 1.04, 95\% $\mathrm{Cl} 1.01$ to 1.08) as well as an association with pre-eclampsia (OR $1.04,95 \% \mathrm{Cl}$ 1.01 to 1.08 ), per $10 \mu \mathrm{g} / \mathrm{m}^{3}$ increase in $\mathrm{O}_{3}$. We observed no association between first trimester $\mathrm{NO}_{\mathrm{x}}$ and adverse pregnancy outcomes. No associations were observed between any of the air pollutants and small for gestational age.

Conclusions: Increased levels of $\mathrm{O}_{3}$ during the first trimester increased the risk of pre-eclampsia and preterm birth. Air pollutants did not exhibit any effects on fetal growth restriction. We estimated 1 in every 20 cases of pre-eclampsia to be associated with $\mathrm{O}_{3}$ exposure.

\section{INTRODUCTION}

Preterm birth, defined as being born before 37 weeks of gestation, is an important predictor of morbidity and educational performance throughout childhood and adult life. ${ }^{1-3}$ An emerging body of evidence indicates that there is an association between temporal variations in air pollution levels and preterm birth. $^{4-15}$ Positive associations have been reported for exposure to high levels of air

\section{ARTICLE SUMMARY}

Article focus

- Does early gestation air pollution exposure, in particular ozone $\left(\mathrm{O}_{3}\right)$, affect the risk of adverse birth outcomes (ie, pre-eclampsia, preterm birth and small for gestational age)?

Key messages

- This large European study adds to the evidence that preterm birth may be caused by $\mathrm{O}_{3}$ exposure, and that the effect may be greater among asthmatic mothers.

- This is one of the first studies to show an association between $\mathrm{O}_{3}$ and pre-eclampsia.

- Health impact assessment of $\mathrm{O}_{3}$ exposure should include also effects on pregnancy outcomes.

Strengths and limitations of this study

- Temporal fluctuations in air pollution exposure are unlikely correlated to individual level risk factors, however still accounted for in order to improve the model performance.

- This study uses valid estimates of temporal variation in $\mathrm{O}_{3}$ exposure, adjusts for seasonality, but does not take into account any spatial variation in the traffic pollutants.

pollution during early ${ }^{4} \quad 10-1315$ and late gestation. $^{5-7}$ 9-12 $14 \quad 15$ A study from Stockholm in Sweden on temporal variation adjusted for season showed a positive association between exposure to higher ground level ozone $\left(\mathrm{O}_{3}\right)$ levels during the first trimester and an increased incidence of preterm birth. ${ }^{16}$ A recent study from Scania in Sweden reported a negative association between modelled nitrogen oxide $\left(\mathrm{NO}_{\mathrm{x}}\right)$ levels and preterm birth when studying spatial variation (using $500 \times 500 \mathrm{~m}$ grids). No evidence for an association with fetal growth was shown, but the study did not investigate the effect of $\mathrm{O}_{3} \cdot{ }^{17}$ Most recent European studies on air pollution and pregnancy outcomes were small and focused on within-city variations in traffic-generated pollution. ${ }^{18} 19$ 
The descriptor 'small for gestational age' (SGA) includes genetically small infants and intrauterine growth-restricted infants. There is no international consensus on the definition of SGA, and the most common ones either include infants who weigh less than the 10th percentile at a specified gestational age ${ }^{2021}$ or infants weighing less than 2 SDs below the mean of the population at a specified gestational age. Intrauterine growth restriction can be defined as a failure to reach the genetically predetermined optimal growth potential and is a more clinically relevant evaluation in relation to SGA. Pre-eclampsia, pregnancy-induced hypertension, smoking and placental insufficiency are risk factors for SGA. ${ }^{22} 23$ A study from Valencia in Spain on the association between spatiotemporal variations in vehicle exhaust emissions and SGA reported an increased risk of SGA when the mother had been exposed to elevated levels of vehicle exhaust $\left(\mathrm{NO}_{2}\right){ }^{24}$ A study from New Jersey reported a positive association between the first and third trimester levels of air pollution particles smaller than $2.5 \mu \mathrm{m}\left(\mathrm{PM}_{2.5}\right)$ and SGA, using $\mathrm{PM}_{2.5}$ values from the closest monitoring station. $^{25}$

Pre-eclampsia is a potentially devastating, pregnancyrelated, multisystem disorder that complicates 3-8\% of pregnancies in Western countries and resolves at delivery of the placenta. ${ }^{23}{ }^{26}$ Pre-eclampsia is characterised by hypertension and proteinuria resulting from abnormal placentation, but is most likely a heterogeneous collection of disease entities that share some common features. ${ }^{27}$ Prominent risk factors for the development of pre-eclampsia are nulliparity, previous chronic hypertension, kidney disease, diabetes mellitus, obesity, twin pregnancy, molar pregnancy and congenital fetal abnormalities. ${ }^{23}$ Few factors are known to counteract preeclampsia; however, smoking has been shown to decrease the risk. ${ }^{28}$ It is estimated that pre-eclampsia accounts for around $15 \%$ of preterm births. ${ }^{27} \mathrm{~A}$ few studies have reported an association between spatial air pollution variation and pre-eclampsia. Thus, a study from Southern California reported that traffic-related air pollution was positively associated with pre-eclampsia, ${ }^{29}$ and a Dutch study showed a positive association between such pollution and pregnancy-induced hypertension. ${ }^{30}$

A recent meta-analysis indicated that pregnant women with asthma are at a significantly increased risk of a range of adverse perinatal outcomes, including low birth weight, SGA, preterm delivery and pre-eclampsia. ${ }^{31}$ Several potential mechanisms are plausible. Poor control of asthma might increase the risk of preterm delivery and pre-eclampsia via maternal hypoxia, thereby hampering fetal oxygenation, or might involve the release of inflammatory mediators from the mother. Air pollution exposure might also lead to an inflammatory response, ${ }^{32}$ and trophoblastic invasion during formation of the placenta might be disrupted by proinflammatory cytokines. ${ }^{13} 33$ This can also lead to pre-eclampsia, an important predictor of preterm birth. ${ }^{34}$

Most studies on preterm birth have been conducted in cities where the ambient air pollution levels are often very high. Therefore, our main aim was to study the possible associations between exposure to $\mathrm{O}_{3}$ and traffic-related air pollutants during early gestation and the pregnancy outcomes of preterm birth, SGA and pre-eclampsia in Stockholm, a city with relatively clean air. $\mathrm{NO}_{\mathrm{x}}$ was chosen as a proxy for vehicle exhaust, and $\mathrm{O}_{3}$ was chosen because it is a reactive gas known to cause inflammation and has large-scale temporal fluctuations. We focused on exposure to air pollutants during the first trimester because first trimester $\mathrm{O}_{3}$ was associated with preterm birth in the previous Stockholm study, ${ }^{16}$ and since oxidative stress may lead to pre-eclampsia, we also wanted to study this outcome in relation to $\mathrm{O}_{3}$. Furthermore, we explored whether pregnant women with asthma were more likely to give birth preterm when exposed to higher air pollution levels during early gestation, compared with the rest of the population.

\section{MATERIALS AND METHODS \\ Register data}

Data on all deliveries in the Greater Stockholm area during 1998 through 2006 were extracted from the Swedish Medical Birth Register $(\mathrm{n}=134$ 802). The Swedish Medical Birth Register includes information on maternal age and height, weight, family situation, tobacco use, country of origin and medical diagnoses. Data on children include sex, height, length, APGAR score and medical diagnoses. Data on parity (number of previous children), gestational age and mode of delivery (including caesarean section) are also available. In the final dataset, we included all singleton pregnancies conceived at the earliest in August 1997 and at the latest in February 2006 and who were delivered at any of the five hospitals in the Greater Stockholm area $(n=120755)$. The first trimester was defined as the first 12 weeks of gestation. From the patient register, we extracted data on all mothers with inpatient care for bronchial asthma from 1990 to 2010 and outpatient care from 2001 to 2010. We extracted data on asthma medication from July 2005 to December 2011 from the Swedish Prescribed Drug Register.

Gestational age was estimated mainly by dating using ultrasound examinations, or by calculating gestational age in relation to the mother's last recalled menstrual period. Preterm birth was defined as the neonate being born prior to gestational week 37. SGA was defined as having a birth weight below the 10th percentile for each gestational age in days. We constructed a pre-eclampsia variable including pregnancy-induced hypertension and eclampsia, using the International Classification of Diseases V.10 (ICD-10) and including the diagnoses O11, O13, O14 and O15. The mother was defined as having asthma if she had ever had a hospital visit caused by bronchial asthma or if she had been prescribed medication for it (Anatomical Therapeutic Chemical, ATC medication codes R03AC, R03AK, R03BA, R03BC, R03CC and R03DC). The body mass index (BMI) was 
calculated as the weight $(\mathrm{kg})$ divided by the height squared $\left(\mathrm{m}^{2}\right)$.

\section{Exposure data}

Data on $\mathrm{O}_{3}$ and $\mathrm{NO}_{\mathrm{x}}$, as indicators of traffic pollution, were provided by the City of Stockholm Environment and Health Administration. $\mathrm{O}_{3}$ data from two monitoring stations were used. Measurements from three different monitoring stations, all at roof level, were used for $\mathrm{NO}_{\mathrm{x}}$. Measurements of ozone were based on its absorption of ultraviolet light (UV Absorption Ozone Analyzer, model 42M; Environnement S.A, Poissy, France). $\mathrm{NO}_{\mathrm{x}}$ was measured using a chemiluminescence-based instrument (AC 30M, Environnement S.A). All measurements were done at background monitoring stations. Measurements from three monitoring stations were used to obtain data on ambient temperature (in ${ }^{\circ} \mathrm{C}$ ) and relative humidity (\%). For $\mathrm{NO}_{\mathrm{x}}$ and the meteorological variables, daily mean values were calculated for each monitoring station if no more than $25 \%$ of the observations were missing. For $\mathrm{O}_{3}$, daily $8 \mathrm{~h}$ maxima were used. In cases of missing daily values at any monitoring station, a new value was imputed from the other monitoring station using linear regression. If there were missing data for more than one monitoring station, no imputation was performed. Daily city-wide levels were then calculated using all monitoring stations. Mean pollution levels and average levels for the meteorological variables were calculated for the first trimester of gestation for each pregnancy if fewer than 20 days of daily averages were missing during the period. In all, 5124 $(4.2 \%)$ of the study subjects were not assigned any relative humidity exposure.

\section{Statistical analysis}

Logistic regression was used to quantify adjusted and unadjusted associations between the air pollution levels and pregnancy outcomes. To adjust for potential confounding, we adjusted for season of conception as a smooth cyclic function, year of conception as a smooth function, first trimester average temperature and relative humidity as linear predictors; $95 \%$ CI were used to evaluate the uncertainty of the estimated associations. The attributable fraction was estimated by multiplying the exposure prevalence among cases, $\mathrm{p}$, with the OR-1 divided by the OR $\mathrm{p}(\mathrm{OR}-1) / \mathrm{OR}$. Being exposed was defined as having an air pollution level higher than the 25th percentile, meaning that the OR in the formula was the OR for an increase from the 25th percentile to the average air pollution exposure above the 25th percentile.

To improve the performance of the models, we adjusted for maternal asthma, maternal age, current maternal smoking at registration in antenatal care, maternal education, BMI at registration in antenatal care, family situation, area of origin, sex of the child and parity. Maternal age was adjusted for as a smooth function. Maternal smoking was used as a three-level factor variable: non-smoker, moderate smoker (1-9 cigarettes/day) and heavy smoker (>10 cigarettes/day). BMI in $\mathrm{kg} / \mathrm{m}^{2}$ was used as a factor with levels according to the standard limits defined by the WHO: underweight $(<18.5)$, normal weight $(>18.5$ and $<25)$, overweight $(>25$ and $<30)$ and obese $(\geq 30)$. Family situation was a three-level factor variable: cohabiting with the father, living alone and any other family situation. The factor levels for region of origin were: Africa, Asia and Oceania, Central and South America, Europe, Middle East, North America and the Nordic countries. The level of education was a five-level factor; pre-upper secondary school (9 years), upper secondary school (2 years), post-upper secondary school ( $<3$ years), postsecondary school (3 years) and postgraduate education. Parity was a four-level factor: 1, 2, 3 and 4 or more children. Maternal asthma was assumed to be a dichotomous variable.

Each model was developed in six steps. First trimester $\mathrm{O}_{3}$ or $\mathrm{NO}_{\mathrm{x}}$ were the only variables in the initial unadjusted model. In the second step (model 2), we added maternal age, parity, index pregnancy resulting in the studied outcome, level of education, area of origin, maternal asthma and season of conception. The next step in model 3 was to add the year of conception. Next, we added the mean first trimester $\mathrm{NO}_{\mathrm{x}}$ or $\mathrm{O}_{3}$ to generate model 4 . In model 5 , we added the average first trimester temperature and the average first trimester relative humidity to the model. The final step in model 6 was to add maternal smoking status, family situation and BMI at first antenatal care visit to the model. These data were added at the last step because they suffered from nonrandom missing values. This analysis was performed on the total material and on a subset of data where all elective caesarean sections were excluded. To assess whether mothers with asthma were extra-sensitive to $\mathrm{O}_{3}$ exposure during the first trimester of pregnancy with regard to preterm birth, we added an interaction term for asthma and $\mathrm{O}_{3}$ in each step in the modelling procedure outlined above. All statistical analysis was performed in R statistical software V.2.13.0.

Ethics approval was granted by the Regional Ethical Review Board in Umeå.

\section{RESULTS}

The median duration of gestation was 40 weeks and 1 day. The proportion of preterm deliveries was $4.4 \%$ during the study period. This varied slightly, depending on the origin of the mother, with the lowest proportion being found among mothers from Europe $(3.7 \%)$ and the highest among mothers born in Asia, excluding the Middle East (5.6\%) (see online supplementary table S1). The proportion of preterm deliveries varied during the study period with the highest prevalence in 1999 (4.9\%), a lower prevalence in 2000-2004 and a higher prevalence towards the end of the study period. The time trend for pre-eclampsia was similar but with a smaller variation. The overall prevalence of pre-eclampsia was $2.7 \%$. 
The proportion of study subjects with missing data on smoking, maternal BMI and family situation varied during the study period, with the highest proportion of missing data in 1997, 1999 and 2003-2006. For all years except one, the excluded subjects had a first trimester mean $\mathrm{O}_{3}$ deviating $1.5 \%$ or less from the included subjects.

The $\mathrm{O}_{3}$ levels varied strongly with season, with the highest first trimester average recorded in pregnancies with conception dates during February-April, and the lowest in pregnancies with conception dates during September-November. The $\mathrm{O}_{3}$ levels were lower in the beginning of the study period and higher towards the end, with peaks in 1999 and 2002. The $\mathrm{NO}_{\mathrm{x}}$ levels varied slightly with season, with the highest being recorded in pregnancies with conception dates during AugustOctober. The overall $\mathrm{NO}_{\mathrm{x}}$ level decreased throughout the study period. $\mathrm{O}_{3}$ and $\mathrm{NO}_{\mathrm{x}}$ were negatively correlated, $\mathrm{r}=-0.48$. The correlation between $\mathrm{O}_{3}$ and temperature was 0.38 , and the correlation between $\mathrm{O}_{3}$ and relative humidity was -0.86 . The correlation between $\mathrm{NO}_{\mathrm{x}}$ and temperature was -0.29 , and the correlation between $\mathrm{NO}_{\mathrm{x}}$ and relative humidity was 0.37 .

Higher levels of the first trimester $\mathrm{O}_{3}$ were associated with higher odds of the offspring being born preterm. The OR for being born preterm was 1.03 (95\% CI 1.01 to 1.06) per $10 \mu \mathrm{g} / \mathrm{m}^{3}$ increase in $\mathrm{O}_{3}$ in the unadjusted model (table 1). The estimated OR changed slightly when adjusting for maternal age, parity, level of education, area of origin, maternal asthma and season of conception: OR 1.04 (95\% CI 1.01 to 1.07 ) per $10 \mu \mathrm{g} / \mathrm{m}^{3}$ increase. The estimate did not change when adjusting for the year of conception: OR 1.04 (95\% CI 1.01 to 1.08 ) per $10 \mu \mathrm{g} / \mathrm{m}^{3}$ increase in $\mathrm{O}_{3}$. Adding the first trimester $\mathrm{NO}_{\mathrm{x}}$ to this model did not alter the estimated OR of experiencing a preterm birth. When the first trimester temperature and relative humidity were added to this model, the OR of preterm birth became 1.05 per $10 \mu \mathrm{g} / \mathrm{m}^{3}$, but it was less precise because of collinearity (95\% CI 0.99 to 1.11$)$. When we included maternal smoking, family situation and BMI at the first antenatal care visit, the estimated association between $\mathrm{O}_{3}$ and preterm birth did not change: OR 1.04 (95\% CI 0.98 to 1.10 ) per $10 \mu \mathrm{g} / \mathrm{m}^{3}$ increase.

The association between $\mathrm{O}_{3}$ level and preterm birth became stronger when we excluded elective caesarean sections from the dataset (table 1). The OR from the unadjusted model was 1.04 (95\% CI 1.01 to 1.06$)$ per $10 \mu \mathrm{g} / \mathrm{m}^{3}$ increase. When we adjusted for maternal age, parity, level of education, area of origin, maternal asthma, season of conception, conception year, first trimester $\mathrm{NO}_{\mathrm{x}}$ level, temperature and relative humidity, the OR was 1.11 (95\% CI $1.02-1.21)$ per $10 \mu \mathrm{g} / \mathrm{m}^{3}$ increase. Including maternal smoking and BMI at the first antenatal care visit yielded an OR of 1.07 (95\% CI 0.99 to 1.15) per $10 \mu \mathrm{g} / \mathrm{m}^{3}$ increase. We also tested to add preeclampsia as a covariate in the analysis of preterm birth; although it was a strong risk factor (OR 2.5) in the model, the effect on the association between $\mathrm{O}_{3}$ and preterm birth was negligible.

We observed little or no support for an association between first trimester $\mathrm{NO}_{\mathrm{x}}$ exposure and preterm birth (table 1). In the unadjusted model, the OR was 0.99 (95\% CI 0.98 to 1.01 ) per $10 \mu \mathrm{g} / \mathrm{m}^{3}$ increase. When we adjusted for maternal age, parity, level of education, area of origin, maternal asthma, season of conception, conception year, first trimester $\mathrm{NO}_{\mathrm{x}}$ level, temperature and relative humidity, the estimated OR was 1.02 (95\% CI 0.99 to 1.06$)$ per $10 \mu \mathrm{g} / \mathrm{m}^{3}$ increase.

There was an indication that the association between $\mathrm{O}_{3}$ and preterm birth was stronger among mothers suffering from asthma than among the rest of the population, although the difference was not statistically significant (table 2). The ORs from the unadjusted model were 1.03 (95\% CI 1.01 to 1.05 ) for the non-

Table 1 OR for preterm birth per $10 \mu \mathrm{g} / \mathrm{m}^{3}$ increase in the first trimester $\mathrm{O}_{3}$ and/or the first trimester $\mathrm{NO}_{\mathrm{x}}$ levels

\begin{tabular}{|c|c|c|c|c|c|c|}
\hline & $\mathbf{N}$ & OR & $95 \% \mathrm{Cl}$ & $n^{*}$ & OR $^{*}$ & $95 \% \mathrm{Cl}^{*}$ \\
\hline $\mathrm{O}_{3}$ unadjusted model & 120745 & 1.03 & 1.01 to 1.06 & 100812 & 1.04 & 1.01 to 1.06 \\
\hline $\mathrm{O}_{3}$ model $2 \dagger$ & 120251 & 1.04 & 1.01 to 1.07 & 100408 & 1.04 & 1.00 to 1.08 \\
\hline $\mathrm{O}_{3}$ model $3 \ddagger$ & 120251 & 1.04 & 1.01 to 1.08 & 100408 & 1.09 & 1.03 to 1.16 \\
\hline $\mathrm{O}_{3}$ model $4 \S$ & 120251 & 1.04 & 1.01 to 1.08 & 100408 & 1.07 & 1.02 to 1.12 \\
\hline $\mathrm{O}_{3}$ model 59 & 115148 & 1.05 & 0.99 to 1.11 & 95817 & 1.11 & 1.02 to 1.21 \\
\hline $\mathrm{O}_{3}$ model $6^{\star \star}$ & 86983 & 1.04 & 0.98 to 1.10 & 73267 & 1.07 & 0.99 to 1.15 \\
\hline $\mathrm{NO}_{\mathrm{x}}$ unadjusted model & 120745 & 0.99 & 0.98 to 1.01 & 100812 & 0.99 & 0.97 to 1.01 \\
\hline $\mathrm{NO}_{x}$ model $2 \dagger$ & 120251 & 1.00 & 0.98 to 1.02 & 100408 & 1.00 & 0.98 to 1.02 \\
\hline $\mathrm{NO}_{\mathrm{x}}$ model $3 \ddagger$ & 120251 & 1.02 & 0.99 to 1.06 & 100408 & 1.04 & 0.99 to 1.08 \\
\hline $\mathrm{NO}_{x}$ model $4 \S$ & 120251 & 1.01 & 0.98 to 1.05 & 100408 & 1.03 & 0.99 to 1.07 \\
\hline $\mathrm{NO}_{\mathrm{x}}$ model 5ा & 115148 & 1.02 & 0.99 to 1.06 & 95817 & 1.02 & 0.97 to 1.07 \\
\hline $\mathrm{NO}_{\mathrm{x}}$ model $6^{\star *}$ & 86983 & 1.01 & 0.97 to 1.06 & 73267 & 1.01 & 0.96 to 1.07 \\
\hline
\end{tabular}

${ }^{*}$ Elective caesarean section deliveries were excluded from the analysis.

†Single pollutant model adjusted for maternal age, parity, level of education, area of origin, maternal asthma and season of conception.

fSingle pollutant model adjusted for everything in $\dagger$ and conception year.

§Multiple pollutant model adjusted for $\dagger$ and $¥$.

ПMultiple pollutant model adjusted for $\uparrow-\S$, first trimester temperature and first trimester relative humidity.

${ }_{\star *}$ Multiple pollutant model adjusted for $\uparrow-\uparrow$, maternal smoking, family situation and BMl at the first antenatal care visit. 
Table 2 ORs for preterm birth among non-asthmatic and asthmatic mothers per $10 \mu \mathrm{g} / \mathrm{m}^{3}$ increase in the first trimester $\mathrm{O}_{3}$ levels

\begin{tabular}{|c|c|c|c|c|c|}
\hline & Group & OR & $95 \% \mathrm{Cl}$ & OR $^{\star}$ & $95 \% \mathrm{Cl}^{*}$ \\
\hline $\mathrm{O}_{3}$ unadjusted model & Non-asthmatic & 1.03 & 1.01 to 1.05 & 1.03 & 1.00 to 1.05 \\
\hline $\mathrm{O}_{3}$ unadjusted model & Asthmatic & 1.07 & 1.01 to 1.14 & 1.09 & 1.02 to 1.16 \\
\hline $\mathrm{O}_{3}$ model $2 \dagger$ & Non-asthmatic & 1.04 & 1.00 to 1.08 & 1.08 & 1.02 to 1.15 \\
\hline $\mathrm{O}_{3}$ model $2 \dagger$ & Asthmatic & 1.08 & 1.01 to 1.15 & 1.14 & 1.05 to 1.24 \\
\hline $\mathrm{O}_{3}$ model $3 \ddagger$ & Non-asthmatic & 1.04 & 1.00 to 1.08 & 1.06 & 1.01 to 1.11 \\
\hline $\mathrm{O}_{3}$ model $3 \ddagger$ & Asthmatic & 1.08 & 1.01 to 1.15 & 1.12 & 1.04 to 1.21 \\
\hline $\mathrm{O}_{3}$ model $4 \S$ & Non-asthmatic & 1.05 & 0.99 to 1.11 & 1.11 & 1.01 to 1.21 \\
\hline $\mathrm{O}_{3}$ model $4 \S$ & Asthmatic & 1.08 & 1.00 to 1.17 & 1.16 & 1.04 to 1.29 \\
\hline $\mathrm{O}_{3}$ model $5 \rrbracket$ & Non-asthmatic & 1.04 & 0.98 to 1.10 & 1.07 & 0.99 to 1.15 \\
\hline $\mathrm{O}_{3}$ model 50 & Asthmatic & 1.04 & 0.96 to 1.14 & 1.09 & 0.98 to 1.20 \\
\hline
\end{tabular}

${ }^{*}$ Elective caesarean section excluded from the analysis.

†Adjusted for maternal age, parity, level of education, area of origin, maternal asthma, conception year and season of conception.

$\ddagger$ Adjusted for $\dagger$ and first trimester $\mathrm{NO}_{x}$.

$\S$ Adjusted for $\dagger$ and $\ddagger$ and first trimester temperature and relative humidity.

ๆAdjusted for $\dagger-\S$, maternal smoking, family situation and BMI at the first antenatal care visit.

asthmatic mothers and 1.07 (95\% CI 1.01 to 1.14 ) for the asthmatic mothers per $10 \mu \mathrm{g} / \mathrm{m}^{3}$ increase. When we adjusted for maternal age, parity, level of education, region of origin, season of conception, conception year, first trimester $\mathrm{NO}_{\mathrm{x}}$, temperature and relative humidity, the OR was 1.05 (95\% CI 0.99 to 1.11) among nonasthmatic mothers and 1.08 (95\% CI 1.00 to 1.17) among asthmatic mothers per $10 \mu \mathrm{g} / \mathrm{m}^{3}$ increase in $\mathrm{O}_{3}$. Including maternal smoking, family situation and BMI at the first antenatal care visit yielded an OR of $1.04(95 \%$ CI 0.98 to 1.10 ) among non-asthmatic mothers and an OR of 1.04 (95\% CI 0.96 to 1.14) among asthmatic mothers per $10 \mu \mathrm{g} / \mathrm{m}^{3}$ increase in $\mathrm{O}_{3}$. In addition, maternal asthma in itself was associated with an OR of 1.25 (95\% CI 1.13 to 1.38) in the fully adjusted model.

There was no indication of an adverse effect of exposure to higher levels of $\mathrm{O}_{3}$ during the first trimester with regard to the incidence of SGA (table 3). We also observed no association between higher first trimester $\mathrm{NO}_{\mathrm{x}}$ levels and SGA.

Higher first trimester $\mathrm{O}_{3}$ levels were positively associated with pre-eclampsia (table 4 ). The estimated OR was $1.04(95 \%$ CI 1.02 to 1.07$)$ per $10 \mu \mathrm{g} / \mathrm{m}^{3}$ increase in $\mathrm{O}_{3}$ in the unadjusted model. When we adjusted for maternal age, parity, level of education, area of origin, maternal asthma, season of conception, conception year, first trimester $\mathrm{NO}_{\mathrm{x}}$ level, temperature and relative humidity, the OR became 1.12 (95\% CI 1.04 to 1.20$)$ per $10 \mu \mathrm{g} / \mathrm{m}^{3}$ increase in $\mathrm{O}_{3}$. Adjusting for smoking habits, family situation and BMI at the first antenatal care visit resulted in an OR of 1.08 (95\% CI 0.99 to 1.19$)$ per $10 \mu \mathrm{g} / \mathrm{m}^{3}$ increase in $\mathrm{O}_{3}$. There was no suggestion that higher levels of first trimester $\mathrm{O}_{3}$ were more strongly associated with pre-eclampsia among mothers with asthma

Table 3 OR for birth of small for gestational age neonates per $10 \mu \mathrm{g} / \mathrm{m}^{3}$ increase in the first trimester $\mathrm{O}_{3}$ and/or the first trimester $\mathrm{NO}_{\mathrm{x}}$

\begin{tabular}{|c|c|c|c|c|c|c|}
\hline & $\mathbf{N}$ & OR & $95 \% \mathrm{Cl}$ & $\mathrm{n}^{*}$ & OR $^{*}$ & $95 \% \mathrm{Cl}^{*}$ \\
\hline $\mathrm{O}_{3}$ unadjusted model & 120535 & 0.99 & 0.97 to 1.00 & 100635 & 0.99 & 0.97 to 1.00 \\
\hline $\mathrm{O}_{3}$ model $2 \dagger$ & 120042 & 0.99 & 0.98 to 1.01 & 100232 & 0.99 & 0.97 to 1.01 \\
\hline $\mathrm{O}_{3}$ model $3 \ddagger$ & 120042 & 0.99 & 0.98 to 1.01 & 100232 & 0.99 & 0.97 to 1.00 \\
\hline $\mathrm{O}_{3}$ model $4 \S$ & 120042 & 0.98 & 0.97 to 1.00 & 100232 & 0.98 & 0.96 to 1.00 \\
\hline $\mathrm{O}_{3}$ model $5 \rrbracket$ & 114944 & 0.99 & 0.95 to 1.03 & 95646 & 0.98 & 0.94 to 1.03 \\
\hline $\mathrm{O}_{3}$ model $6^{\star \star}$ & 86825 & 0.99 & 0.95 to 1.04 & 73132 & 0.98 & 0.93 to 1.03 \\
\hline $\mathrm{NO}_{\mathrm{x}}$ unadjusted model & 120535 & 1.00 & 0.99 to 1.02 & 100635 & 1.00 & 0.98 to 1.01 \\
\hline $\mathrm{NO}_{\mathrm{x}}$ model $2 \dagger$ & 120042 & 0.99 & 0.98 to 1.00 & 100232 & 0.98 & 0.97 to 1.00 \\
\hline $\mathrm{NO}_{\mathrm{x}}$ model $3 \ddagger$ & 120042 & 0.97 & 0.94 to 0.99 & 100232 & 0.97 & 0.94 to 1.00 \\
\hline $\mathrm{NO}_{\mathrm{x}}$ model $4 \S$ & 120042 & 0.97 & 0.95 to 0.99 & 100232 & 0.97 & 0.95 to 1.00 \\
\hline $\mathrm{NO}_{\mathrm{x}}$ model 5ा & 114944 & 0.98 & 0.95 to 1.00 & 95646 & 0.98 & 0.95 to 1.01 \\
\hline $\mathrm{NO}_{\mathrm{x}}$ model $6^{* \star}$ & 86825 & 0.98 & 0.95 to 1.00 & 73132 & 0.98 & 0.95 to 1.01 \\
\hline
\end{tabular}

*Elective caesarean sections were excluded from the analysis.

†Single pollutant model adjusted for maternal age, parity, level of education, area of origin, maternal asthma and season of conception

†Single pollutant model adjusted for everything in $\dagger$ and for conception year.

§Multiple pollutant model adjusted for $\dagger$ and $\ddagger$.

ףMultiple pollutant model adjusted for $\dagger-\S$, first trimester temperature and first trimester relative humidity.

${ }^{\star *}$ Multiple pollutant model adjusted fort- $\uparrow$, maternal smoking, family situation and BMI at the first antenatal care visit. 
Table 4 ORs for pre-eclampsia per $10 \mu \mathrm{g} / \mathrm{m}^{3}$ increase in the first trimester $\mathrm{O}_{3}$ and/or the first trimester $\mathrm{NO}_{\mathrm{x}}$ levels

\begin{tabular}{|c|c|c|c|c|c|c|}
\hline & $\mathbf{N}$ & OR & $95 \% \mathrm{Cl}$ & $n^{*}$ & OR $^{*}$ & $95 \% \mathrm{Cl}^{*}$ \\
\hline $\mathrm{O}_{3}$ unadjusted model & 120755 & 1.04 & 1.02 to 1.07 & 100819 & 1.04 & 1.01 to 1.07 \\
\hline $\mathrm{O}_{3}$ model $2 \uparrow$ & 120261 & 1.05 & 1.02 to 1.07 & 100415 & 1.04 & 1.01 to 1.07 \\
\hline $\mathrm{O}_{3}$ model $3 \ddagger$ & 120261 & 1.05 & 1.02 to 1.08 & 100415 & 1.04 & 1.01 to 1.07 \\
\hline $\mathrm{O}_{3}$ model $4 \S$ & 120261 & 1.04 & 1.01 to 1.08 & 100415 & 1.03 & 1.00 to 1.07 \\
\hline $\mathrm{O}_{3}$ model 5ף & 115158 & 1.11 & 1.03 to 1.20 & 95824 & 1.15 & 1.05 to 1.25 \\
\hline $\mathrm{O}_{3}$ model $6^{\star *}$ & 86993 & 1.08 & 0.98 to 1.18 & 73278 & 1.10 & 0.98 to 1.22 \\
\hline $\mathrm{NO}_{\mathrm{x}}$ unadjusted model & 120755 & 0.99 & 0.97 to 1.01 & 100819 & 0.98 & 0.96 to 1.01 \\
\hline $\mathrm{NO}_{x}$ model $2 \dagger$ & 120261 & 0.99 & 0.97 to 1.02 & 100415 & 0.99 & 0.96 to 1.01 \\
\hline $\mathrm{NO}_{\mathrm{x}}$ model $3 \ddagger$ & 120261 & 0.98 & 0.94 to 1.03 & 100415 & 0.96 & 0.92 to 1.00 \\
\hline $\mathrm{NO}_{\mathrm{x}}$ model $4 \S$ & 120261 & 0.99 & 0.95 to 1.03 & 100415 & 0.98 & 0.93 to 1.02 \\
\hline $\mathrm{NO}_{\mathrm{x}}$ model 5ף & 115158 & 1.00 & 0.95 to 1.04 & 95824 & 1.01 & 0.95 to 1.06 \\
\hline $\mathrm{NO}_{x}$ model $6^{* *}$ & 86993 & 1.00 & 0.93 to 1.07 & 73278 & 0.99 & 0.91 to 1.07 \\
\hline
\end{tabular}

*Elective caesarean sections were excluded from the analysis.

†Single pollutant model adjusted for maternal age, parity, level of education, area of origin, maternal asthma and season of conception.

$\ddagger$ Single pollutant model adjusted for everything in tand conception year.

$\S$ Multiple pollutant model adjusted for $\dagger$ and $\ddagger$.

ๆMultiple pollutant model adjusted for $\dagger-\S$, first trimester temperature and first trimester relative humidity.

${ }^{\star *}$ Multiple pollutant model adjusted for $\uparrow-\emptyset$, maternal smoking, family situation and BMI at the first antenatal care visit.

than among those without: OR 1.05 (95\% CI 1.02 to 1.08) for non-asthmatic mothers and 1.01 (95\% CI 0.93 to 1.08) for asthmatic mothers in the unadjusted model per $10 \mu \mathrm{g} / \mathrm{m}^{3}$ increase in $\mathrm{O}_{3}$. When we adjusted for maternal age, parity, level of education, region of origin, which day during the year conception occurred, conception year, first trimester $\mathrm{NO}_{\mathrm{x}}$ level, temperature and relative humidity, the OR was 1.12 (95\% CI 1.04 to 1.21) among non-asthmatic mothers and 1.08 (95\% CI 0.97 to 1.19 ) among asthmatic mothers per $10 \mu \mathrm{g} / \mathrm{m}^{3}$ increase in $\mathrm{O}_{3}$. However, maternal asthma in itself was associated with a higher risk of pre-eclampsia, giving an OR of 1.10 (95\% CI 0.97 to 1.25 ) in the fully adjusted model. There was no evidence of an association between first trimester $\mathrm{NO}_{\mathrm{x}}$ levels and pre-eclampsia.

The fraction of pre-eclampsia cases attributable to $\mathrm{O}_{3}$ exposure during the first trimester was estimated to be $5.5 \%$, when comparing the risk at the average $\mathrm{O}_{3}$ level above the 25th percentile with that at the 25 th percentile. This corresponds to 138 out of the 2505 cases and 90521 deliveries exposed to $\mathrm{O}_{3}$ levels exceeding the 25th percentile. For preterm birth, the attributable fraction for the first trimester $\mathrm{O}_{3}$ was $5.2 \%$, or 211 of 4061 cases. To estimate the attributable fraction, we used the OR estimate from our model 3 including all modes of delivery, that is, the single pollutant model adjusted for maternal age, parity, level of education, area of origin, maternal asthma, season and year of conception. The attributable fraction would be similar in all other models, except according to models 5-6, adjusting for meteorology, smoking, family situation and BMI, where it would be greater because the ORs were larger.

\section{DISCUSSION}

The Swedish health data registers at the Swedish National Board of Health and Welfare, along with the population register at Statistics Sweden, offer unique opportunities to conduct scientific studies. Linking the different registers makes it possible to adjust the estimated associations for both medical conditions and social factors at an individual level. The Swedish Medical Birth Register covers approximately $98 \%$ of all pregnancies in Sweden. ${ }^{35}$ The completeness of data varied within the Medical Birth Register for this study: data on delivery and delivery related issues (ie, birth weight and birth date) were almost complete, while data referring to antenatal care visits (ie, smoking status, maternal weight) were missing for a large number of pregnancies.

We focused on studying the association between first trimester air pollution exposure and adverse pregnancy outcomes. Using the average first trimester air pollution exposure attenuates any misclassification caused by, for example, travelling more than with a shorter time window. Our study design makes the detection of an association between a variable that varies strongly over time-such as the $\mathrm{O}_{3}$ level-and the studied outcome quite likely. On the other hand, studying the temporal variation of a variable that varies more strongly in space than in time-such as the $\mathrm{NO}_{\mathrm{x}}$ level-is less likely to find any associations. Restricting the study to temporal variation restricts the possible sources of confounding factors to risk factors that might vary over time. However, other exposure windows than the first trimester may be important for other air pollution effects.

This study adds additional support to the association between first trimester $\mathrm{O}_{3}$ levels and the incidence of preterm birth in Stockholm during 1987-1995, when only vaginally delivered singleton pregnancies were included. ${ }^{16}$ The association between higher levels of $\mathrm{O}_{3}$ and the preterm birth incidence was not sensitive to adjustment for any of the additional variables, although the estimate changed slightly when adjusting the model for meteorological factors. The association was stronger 
when elective caesarean sections were excluded; this might be because these pregnancies were terminated because of pre-existing medical conditions, other complications during pregnancy or psychosocial factors.

The actual asthma status of mothers during pregnancy was not well described by our variables. Nevertheless, we observed a higher susceptibility to the adverse effects of $\mathrm{O}_{3}$ exposure among asthmatic women. Asthma is an inflammatory disease, and it is known that $\mathrm{O}_{3}$ exposure may lead to inflammation and asthma exacerbation. Our hypothesis is that inflammation driven by $\mathrm{O}_{3}$ exposure leads to augmented respiratory symptoms and systemic inflammation in asthmatics, thus causing a larger increase in risk of preterm birth among asthmatic mothers.

There is a discrepancy in the reported association between $\mathrm{O}_{3}$ and the incidence of preterm birth. Thus, studies from North America and London have reported no association, ${ }^{7-9} 143637$ but studies from Australia, China and Sweden have done so. ${ }^{13} 16 \quad 38$ Recently, a study from Pittsburgh was the first from the USA to report an association between the first trimester ozone exposure concentrations and the incidence of preterm birth. ${ }^{39}$ It is difficult to explain these inconsistent results, but the relationship between measured concentrations and actual exposure might differ because of within-city variations and the use of air conditioning. ${ }^{71}$ No acute effect of exposure to $\mathrm{O}_{3}$ has been reported, but there might be an effect of late gestation exposure to $\mathrm{O}_{3}$ on the incidence of preterm birth. ${ }^{16} 3738$

A recent WHO report has shown the extent to which the rate of preterm birth is on the rise in most countries. After pneumonia, it is now the second leading cause of death globally for children under five. ${ }^{40}$ The report concluded that the cause of a spontaneous preterm birth is often unknown, but it did not discuss increases in traffic-related pollution or $\mathrm{O}_{3}$ levels.

We did not observe any association between higher levels of air pollution and SGA, contrary to several other studies. This might be because SGA is more strongly associated with vehicle exhaust, which has a strong spatial variation, and our study design did not capture this. Alternatively, this could be explained by the fact that most cases of SGA occur during later stages of gestation and are associated more with factors that act late in pregnancy.

Pre-eclampsia was related to elevated levels of vehicle exhaust in a Dutch study. ${ }^{30}$ A study from California reported an association between both vehicle exhaust and $\mathrm{O}_{3}$ and pre-eclampsia. ${ }^{29}$ Some indication of an association between early pregnancy exposure to $\mathrm{PM}_{2.5}$ and $\mathrm{O}_{3}$ and pre-eclampsia/gestational hypertension was reported in a study from Pittsburgh. ${ }^{39}$ The effect estimate in the present study is similar to these published estimates, but because we had almost three times more observations, we can obtain a clearer signal. The observed association between early gestation exposure to elevated $\mathrm{O}_{3}$ levels and pre-eclampsia cannot explain the major part of the preterm births associated with air pollution exposure.

\section{CONCLUSIONS}

We have shown an association between first trimester $\mathrm{O}_{3}$ exposure and the incidence of preterm birth. This association might be more pronounced among pregnant women with asthma. In addition, we have showed a positive association between first trimester $\mathrm{O}_{3}$ exposure and pre-eclampsia. We found no support for the contention that air pollution exposure in early gestation affects fetal growth. These findings merit further investigation on how exposure to air pollution during early gestation might affect the placenta and lead to adverse pregnancy outcomes. A larger proportion of diesel vehicles in our cities is expected to increase both $\mathrm{NO}_{2}$ and $\mathrm{O}_{3}$ levels. The health impact may involve less discussed effects as adverse pregnancy outcomes.

\section{Author affiliations \\ ${ }^{1}$ Department of Public Health and Clinical Medicine, Occupational and Environmental Medicine, Umeå University, Umeå, Sweden \\ ${ }^{2}$ Department of Clinical Science, Obstetrics and Gynaecology, Umeå University, Umeå, Sweden}

Contributors DO (PhD student) and BF (tutor) initiated the study, BF got ethical approval for register linkage and DO completed the database and checked all data. DO, IM and BF together planned the detailed analyses. DO undertook all statistical analyses and drafted the initial manuscript. IM and BF helped to interpret and discuss the results and revise the manuscript. All authors approved the final version of the manuscript.

Funding This project was supported by the CMF (Centre for Environmental Research, 0832336) in Umeå and the Umeå SIMSAM node.

Competing interests None.

Ethics approval Regional Ethical Review Board in Umeå.

Provenance and peer review Not commissioned; externally peer reviewed. Date sharing statement There are no additional data available.

\section{REFERENCES}

1. Vogt $\mathrm{H}$, Lindstrom K, Braback L, et al. Preterm birth and inhaled corticosteroid use in 6- to 19-year-olds: a Swedish national cohort study. Pediatrics 2011;127:1052-9.

2. Lindstrom K, Winbladh B, Haglund B, et al. Preterm infants as young adults: a Swedish national cohort study. Pediatrics 2007;120:70-7.

3. Ekeus C, Lindstrom K, Lindblad F, et al. Preterm birth, social disadvantage, and cognitive competence in Swedish 18- to 19-year-old men. Pediatrics 2010;125:e67-73.

4. Wilhelm M, Ritz B. Local variations in $\mathrm{CO}$ and particulate air pollution and adverse birth outcomes in Los Angeles County, California, USA. Environ Health Perspect 2005;113:1212-21.

5. Suh YJ, Kim H, Seo JH, et al. Different effects of PM10 exposure on preterm birth by gestational period estimated from time-dependent survival analyses. Int Arch Occup Environ Health 2009;82:613-21.

6. Sagiv SK, Mendola P, Loomis D, et al. A time-series analysis of air pollution and preterm birth in Pennsylvania, 1997-2001. Environ Health Perspect 2005;113:602-6.

7. Ritz B, Yu F, Chapa G, et al. Effect of air pollution on preterm birth among children born in Southern California between 1989 and 1993. Epidemiology 2000;11:502-11.

8. Ritz B, Wilhelm M, Hoggatt KJ, et al. Ambient air pollution and preterm birth in the environment and pregnancy outcomes study at the University of California, Los Angeles. Am J Epidemiol 2007;166:1045-52.

9. Liu S, Krewski D, Shi Y, et al. Association between gaseous ambient air pollutants and adverse pregnancy outcomes in Vancouver, Canada. Environ Health Perspect 2003;111:1773-8.

10. Leem J-H, Kaplan BM, Shim YK, et al. Exposures to air pollutants during pregnancy and preterm delivery. Environ Health Perspect 2006;114:905-10. 
11. Jalaludin B, Mannes T, Morgan G, et al. Impact of ambient air pollution on gestational age is modified by season in Sydney, Australia. Environ Health 2007;6:16.

12. Huynh M, Woodruff TJ, Parker JD, et al. Relationships between air pollution and preterm birth in California. Paediatr Perinat Epidemiol 2006;20:454-61.

13. Hansen C, Neller A, Williams G, et al. Maternal exposure to low levels of ambient air pollution and preterm birth in Brisbane, Australia. BJOG 2006;113:935-41.

14. Darrow LA, Klein M, Flanders WD, et al. Ambient air pollution and preterm birth: a time-series analysis. Epidemiology 2009;20:689-98.

15. Bobak M. Outdoor air pollution, low birth weight, and prematurity. Environ Health Perspect 2000;108:173-6.

16. Olsson D, Ekstrom M, Forsberg B. Temporal variation in air pollution concentrations and preterm birth-a population based epidemiological study. Int $J$ Environ Res Public Health 2012;9:272-85.

17. Malmqvist E, Rignell-Hydbom A, Tinnerberg $\mathrm{H}$, et al. Maternal exposure to air pollution and birth outcomes. Environ Health Perspect 2011:119:553-8.

18. Llop S, Ballester F, Estarlich M, et al. Preterm birth and exposure to air pollutants during pregnancy. Environ Res 2010;110:778-85.

19. Gehring U, Wijga AH, Fischer P, et al. Traffic-related air pollution, preterm birth and term birth weight in the PIAMA birth cohort study. Environ Res 2011:111:125-35.

20. De Jong CL, Francis A, Van Geijn HP, et al. Customized fetal weight limits for antenatal detection of fetal growth restriction. Ultrasound Obstet Gynecol 2000;15:36-40.

21. Groom KM, Poppe KK, North RA, et al. Small-for-gestational-age infants classified by customized or population birthweight centiles: impact of gestational age at delivery. Am J Obstet Gynecol 2007;197:239 e1-5.

22. Lau C, Rogers JM. Embryonic and fetal programming of physiological disorders in adulthood. Birth Defects Res C Embryo Today 2004;72:300-12.

23. Uzan J, Carbonnel M, Piconne O, et al. Pre-eclampsia: pathophysiology, diagnosis, and management. Vasc Health Risk Manag 2011;7:467-74.

24. Ballester F, Estarlich M, Iniguez $\mathrm{C}$, et al. Air pollution exposure during pregnancy and reduced birth size: a prospective birth cohort study in Valencia, Spain. Environ Health 2010;9:6.

25. Rich DQ, Demissie K, Lu SE, et al. Ambient air pollutant concentrations during pregnancy and the risk of fetal growth restriction. J Epidemiol Community Health 2009;63:488-96.
26. Myatt L, Webster RP. Vascular biology of preeclampsia. J Thromb Haemost 2009;7:375-84.

27. Kanasaki K, Kalluri R. The biology of preeclampsia. Kidney Int 2009:76:831-7.

28. Wikstrom AK, Stephansson O, Cnattingius S. Tobacco use during pregnancy and preeclampsia risk: effects of cigarette smoking and snuff. Hypertension 2010;55:1254-9.

29. Wu J, Wilhelm M, Chung J, et al. Comparing exposure assessment methods for traffic-related air pollution in an adverse pregnancy outcome study. Environ Res 2011;111:685-92.

30. van den Hooven EH, de Kluizenaar Y, Pierik FH, et al. Air pollution, blood pressure, and the risk of hypertensive complications during pregnancy: the generation R study. Hypertension 2011;57:406-12.

31. Murphy VE, Namazy JA, Powell $\mathrm{H}$, et al. A meta-analysis of adverse perinatal outcomes in women with asthma. BJOG 2011;118:1314-23.

32. Donaldson $\mathrm{K}$, Stone $\mathrm{V}$, Seaton $\mathrm{A}$, et al. Ambient particle inhalation and the cardiovascular system: potential mechanisms. Environ Health Perspect 2001;109(Suppl 4):P523-27.

33. Gitto E, Reiter RJ, Karbownik M, et al. Causes of oxidative stress in the pre- and perinatal period. Biol Neonate 2002;81:146-57.

34. Kannan S, Misra DP, Dvonch JT, et al. Exposures to airborne particulate matter and adverse perinatal outcomes: a biologically plausible mechanistic framework for exploring potential effect modification by nutrition. Environ Health Perspect 2006;114:1636-42.

35. Socialstyrelsen (National Board of Health and Welfare). Utvärdering av svenska födelseregistret (Evaluation of the Swedish Medical Birth Register). Stockholm: National Board of Health and Welfare, 2002.

36. Brauer M, Lencar C, Tamburic L, et al. A cohort study of traffic-related air pollution impacts on birth outcomes. Environ Health Perspect 2008;116:680-6.

37. Lee SJ, Hajat S, Steer PJ, et al. A time-series analysis of any short-term effects of meteorological and air pollution factors on preterm births in London, UK. Environ Res 2008;106:185-94.

38. Jiang LL, Zhang $\mathrm{YH}$, Song GX, et al. A time series analysis of outdoor air pollution and preterm birth in Shanghai, China. Biomed Environ Sci 2007;20:426-31.

39. Lee PC, Roberts JM, Catov JM, et al. First trimester exposure to ambient air pollution, pregnancy complications and adverse birth outcomes in allegheny county, PA. Matern Child Health J 2012. doi: 10.1007/s10995-012-1028-5 [Epub ahead of print].

40. Howson C, Kinney M, Lawn J. Born too soon: the global action report on preterm birth. March of Dimes, PMNCH, Save the Children, Geneva: WHO, World Health Organization, 2012. 